\title{
METEOROLOGISTS' VIEWS ABOUT GLOBAL WARMING A Survey of American Meteorological Society Professional Members
}

\author{
by Neil Stenhouse, Edward Maibach, Sara Cobb, Ray Ban, Andrea Bleistein, Paul Croft, \\ Eugene Bierly, Keith Seitter, Gary Rasmussen, and Anthony Leiserowitz
}

\begin{abstract}
In a survey of AMS members, perceived scientific consensus was the strongest predictor of views on global warming, followed by political ideology, climate science expertise, and perceived organizational conflict.
\end{abstract}

Affiliations: Stenhouse, Maibach, Cobb, and BierlyGeorge Mason University, Fairfax, Virginia; BAN-The Weather Channel, Atlanta, Georgia; BleisteIN-NOAA/Office of the Assistant Secretary for Environmental Observation and Prediction, Washington, D.C.; CROFT-Department of Geology and Meteorology, Kean University, Union, New Jersey; SeItTeR AND RasmusSen-American Meteorological Society, Boston, Massachusetts; LEISEROWITZ-Yale University, New Haven, Connecticut CORRESPONDING AUTHOR: Neil Stenhouse, George Mason University, 4400 University Drive MSN 6A8, Fairfax, VA 22030 E-mail: nstenhou@gmu.edu

The abstract for this article can be found in this issue, following the table of contents.

DOI:10.1175/BAMS-D-13-00091.I

A supplement to this article is available online (10.1175/BAMS-D-13-00091.2)

In final form 19 September 2013

(C)2014 American Meteorological Society
Meteorologists and other experts in atmospheric and related sciences are one group of professionals whose involvement is particularly important. As experts on weather and weather prediction, they will play a variety of important roles in helping other stakeholder groups make informed decisions based on changing expectations about climate and weather. Their technical expertise is complemented by the fact that members of the public see climate scientists and broadcast meteorologists as trustworthy sources of information on climate change (Leiserowitz et al. 2012).

Research conducted to date with meteorologists and other atmospheric scientists has shown that they are not unanimous in their views of climate change. In a survey of Earth scientists, Doran and Zimmerman (2009) found that, while a majority of meteorologists surveyed are convinced humans have contributed to global warming (GW; 64\%), this was a substantially smaller majority than that found among all Earth scientists (82\%). Another survey, by Farnsworth and Lichter (2009), found that $83 \%$ of meteorologists surveyed were convinced humaninduced climate change is occurring, again a smaller majority than among experts in related areas, such as ocean sciences $(91 \%)$ and geophysics (88\%). 
There has been tension in recent years among American Meteorological Society (AMS) members who hold different views on climate change (Schweizer et al. 2011). Some members have expressed that their views, which question the view that humancaused global warming was occurring, are treated with hostility within the AMS (Schweizer et al. 2011). In response to this conflict, the AMS created the Committee to Improve Climate Change Communication (CICCC) (AMS Committee to Improve Climate Change Communication 2011). The CICCC's mission is to bring all constituencies of opinion to the discussion table and to provide venues and modes of interaction that help facilitate respectful and constructive dialogue on climate change. The CICCC's mission does not explicitly include addressing specific areas of climate science or try to influence the outcomes of discussions.

To better understand members' views about climate change and their perception of any remaining conflicts about climate change within AMS membership, the CICCC commissioned George Mason University researchers to survey AMS members; the top-line findings of that survey have been reported elsewhere (Maibach et al. 2012). In this paper, we report the results of two additional sets of analysis. First, to update previous research on the extent to which meteorologists are convinced of human-caused global warming, we conducted a modified replication of Doran and Zimmerman's (2009) study. Next, we tested four specific hypotheses about factors believed to influence meteorologists' views about climate change, specifically their level of certainty that climate change is occurring, their views on whether it is mostly human caused, and their views on how harmful or beneficial its results might be. The four hypothesized influencing factors are climate science expertise, political orientation, perceived scientific consensus, and perceived conflict about climate change within AMS; the specific hypotheses are presented and explained in detail below. Last, we analyzed open-ended responses from survey participants about the nature of the conflict about climate change within AMS; these findings will be reported in a subsequent paper.

LITERATURE REVIEW AND HYPOTHESES. Climate science expertise. Previous research using survey data (Doran and Zimmerman 2009) and citation analysis (Anderegg et al. 2010) has suggested that greater expertise in climate science, measured in terms of academic background and publishing record, is associated with higher conviction that human- caused global warming is occurring. For example, in Doran and Zimmerman's survey study, while only $82 \%$ of the total sample indicated they are convinced that humans have contributed to global warming, $89 \%$ of active publishers in the peer-reviewed scientific literature and $97 \%$ of climate experts who publish primarily on climate change in the peer-reviewed scientific literature indicated they were convinced (Doran and Zimmerman 2009; Kendall Zimmerman 2008). As a result, our first hypothesis is as follows:

H1: As compared with professionals with less expertise in climate change, professionals with more expertise will have higher levels of personal certainty that global warming is happening, will be more likely to view it is as mostly human caused, and will be more likely to view it as harmful rather than beneficial.

Political ideology. Decision making about how to mount an effective societal response to climate change in the United States has been complicated by increasing polarization over the issue, which has occurred largely along political lines. In the late 1990s, similar proportions of liberals and conservatives saw global warming as real; by 2008 (Dunlap and McCright 2008) - and continuing to the present (Leiserowitz et al. 2012)-large differences had emerged such that liberals were more likely to see it as real, and conservatives had become increasingly skeptical. This growing polarization appears not to be caused by differences in scientific understanding-indeed, most Americans know very little about the science of global warming (Leiserowitz et al. 2010) — but rather by differences in political ideology and deeper underlying values (Kahan et al. 2011). Many conservatives see the solutions proposed to mitigate global warming as being more harmful than global warming itself due to their effect on the economy (McCright and Dunlap 2011). Liberals, on the other hand, are more likely to accept the dominant scientific view, as they see the proposed responses to global warming as strengthening activities they value-namely, protection of the environment and regulation of industrial harm.

One might expect scientists' norms of objectivity to prevent their political ideology from influencing their evaluation of scientific findings. Indeed, in one study scientists' opinions on global warming policy responses varied by political ideology, but their views on the basic science did not (Rosenberg et al. 2010). However, other studies suggest scientists' views on science can be influenced by ideology. A survey of members of the American Association for the Advancement of Science showed that conservatives 
differed dramatically from liberals with regard to their views about the science of global warming (Nisbet 2011): $44 \%$ of conservatives saw global warming as mostly due to human activities, compared to about $94 \%$ of liberals. We therefore hypothesized the following:

H2: As compared with professionals with a more conservative political orientation, professionals with a more liberal political orientation will have higher levels of personal certainty that global warming is happening, will be more likely to be view it is as mostly human caused, and will be more likely to view it as harmful rather than beneficial.

Perceived scientific consensus. Public opinion research has shown that only a minority of the public (44\%) agree that "most scientists think global warming is happening" (Leiserowitz et al. 2012, p. 18). Also, preliminary analyses of the data from the present survey found that only $59 \%$ of AMS members agree that $81 \%-100 \%$ of climate scientists think that global warming is happening (Maibach et al. 2012). Members of the public who perceive agreement about global warming among scientific experts are more likely to view global warming as real, human caused, and harmful than people who do not perceive agreement in the scientific community (Ding et al. 2011; Dunlap and McCright 2008; Krosnick et al. 2006). We therefore hypothesized the following:

H3: As compared with professionals who perceive less scientific consensus about global warming, professionals who perceive more scientific consensus will have higher levels of personal certainty that global warming is happening, will be more likely to be view it as mostly human caused, and will be more likely to view it as harmful rather than beneficial.

Perceived conflict. Schweizer et al. (2011) found that broadcast meteorologists who perceived conflict about global warming among their peers had disengaged from the issue, and they reported having done so because of the pressure they felt from committed partisans in the conflict to "choose sides." This finding parallels an argument that has been advanced in the political science literature that increasing levels of polarization in American politics has caused the moderate majority to disengage from political participation (Fiorina and Abrams 2008). One proposed reason for this political disengagement is that moderate voters feel no incentive to participate when they see the debate as primarily being driven by ideological positioning rather than a wish for problem solving (Fiorina and Abrams 2008). Schweizer et al. (2011) found similar sentiments expressed by broadcast meteorologists in relation to conflict about climate change within AMS. We believe that, when members of a professional group (including but not limited to meteorologists) perceive conflict within their peer group, they will withdraw from the conflict by moderating their views on the issue that is causing the conflict.

This moderation of views would entail AMS members on both ends of the spectrum of views shifting closer toward the center. However, because we expected a larger number of members to have begun with views favoring human-caused global warming (prior to perceiving conflict at the AMS), we also expected any moderating influence to result in members revising their views of global warming downward more often than upward. For this reason, when averaged across the whole population of members, we would expect greater perception of conflict to be associated with a reduced level of conviction that human-caused global warming was occurring. We therefore hypothesized the following:

H4: As compared with professionals who perceive less conflict about global warming within the membership base of their professional society, professionals who perceive more conflict will report lower levels of personal certainty that global warming is happening, will be less likely to be view it is as mostly human caused, and will be less likely to view it as harmful rather than beneficial.

METHOD. On 29 December 2011, we e-mailed all 7,197 AMS members for whom AMS had an e-mail address, excluding associate members and student members. The e-mail-signed by the CICCC chairs-requested participation in our survey and provided a link to the web-based survey form (including the consent form). On 6 January 2012, and again on 11 January 2012, participants who had not yet responded received reminders by e-mail. On 27 March 2012, 375 participants who had given one specific answer (to a question on global warming causation) were e-mailed a request to answer one additional question (designed to clarify their view on causation). This question is described further below.

Of the 7,197 people invited to participate, 135 people were ineligible due to invalid addresses. Therefore, the valid denominator of our sample was 7,062 . Of these, 1,854 people completed at least some portion of the survey beyond the consent form, yielding a 
minimum response rate of $26.3 \%$ (which assumes that all nonrespondents were eligible to participate); this is slightly lower than the average rate for web surveys (Shih and Fan 2008). Of the 375 people who were sent the follow-up question, 271 responded. One of these respondents refused to answer the question, for a response rate to the follow-up question of 270 out of 375 , or $72 \%$.

Independent variables. EXPERTISE. To assess climate science expertise, we examined three measures: whether respondents indicated climate science as their area of expertise, their highest degree obtained, and their peer-reviewed publishing record on climate change over the last five years. Using principal axis factor analysis, we found these measures formed a single factor; loadings for all variables were within the acceptable range (Gorsuch 1983). We therefore decided to sum all three variables into an index of climate science expertise. For area of expertise, participants who indicated climate science as their area of expertise were scored 1 ; all others were scored 0 . For highest degree obtained, participants who answered "PhD (or other doctoral degree)" and "MS or MA" were scored 2 and 1, respectively; all others were scored 0 . For publishing record, respondents who said they published more than $50 \%$ of their peer-reviewed papers in the last five years on climate change were scored 2 . We asked whether they had published more or less than $50 \%$ of their papers in climate change to achieve comparability with the results of Doran and Zimmerman (2009), who also used this as one of their measures of expertise. Those who said they published fewer than $50 \%$ of their papers on climate change, or who answered "N/A" to the question on their proportion of climate change papers, were scored 1 . Those who had not published in the last five years were scored 0 . The scores on all three variables were summed, resulting in a composite variable with possible scores ranging from 0 to 5 .

Political ideology. This measure was based on responses to the question, "In general, do you think of yourself as:" to which participants could respond "Very conservative," "Somewhat conservative," "Moderate," "Somewhat liberal," or "Very liberal." The responses were coded $0-4$, respectively.

Perceived consensus. Respondents were asked, "To the best of your knowledge, what proportion of climate scientists think that human-caused global warming is happening?" Response categories were $0 \%-20 \%$,
$21 \%-40 \%, 41 \%-60 \%, 61 \%-80 \%, 81 \%-100 \%$ (coded $1-5$, respectively), and "I don't know enough to say." Respondents who indicated "I don't know" ( $n=156)$ were excluded from the analyses, so that perceived consensus could be analyzed as a single continuous variable. To assess if the exclusion of "Don't know" respondents influenced our findings, we conducted additional analyses with all respondents using dummy coding, a statistical technique that allows noncontinuous variables to be entered into linear regressions. This produced no significant change to the results.

Perceived conflict. Respondents were asked if they agreed or disagreed with the statement, "There is conflict among AMS members on the issue of global warming." Response options were "Strongly disagree," "Somewhat disagree," "Neither agree nor disagree," "Somewhat agree," and "Strongly agree." The responses were coded 0-4, respectively.

Dependent variables. CerTAINTY. To establish the certainty of respondents' views on global warming, we asked two questions. The first asked whether global warming is happening, and the second assessed the respondents' level of certainty that it is happening. The first question was worded as follows: "In this survey, the term "global warming" refers to the premise that the world's average temperature has been increasing over the past 150 years, may be increasing more in the future, and that the world's climate may change as a result. Regardless of the cause, do you think that global warming is happening?" Respondents who answered either "Yes" or "No" were presented with the following certainty assessment item: "How sure are you that global warming [is/is not] happening?" We then calculated a composite measure to capture the responses to the two questions in a single variable. This resulted in a nine-point certainty measure ranging from -4 (Global warming not happening-extremely sure) to +4 (Global warming happening-extremely sure), with zero (Don't know if global warming is happening) as the neutral midpoint.

CAUSE. If respondents indicated they agreed global warming was occurring, we subsequently asked them the question, "Do you think that the global warming that has occurred over the past 150 years has been caused. .." to which they could answer "Mostly by human activity," "Mostly by natural events," "Moreor-less equally by human activity and natural events," "I do not believe we (scientists) know enough yet to 
determine the degree of human or natural causation, even in the general terms stated in the categories above," and "I don't know."

To make a more precise comparison of our results to those of Doran and Zimmerman (2009), a followup question was posed via e-mail (approximately 10 weeks later) to those who answered, "I do not believe we know enough to determine the degree of human causation." Specifically, we sought to determine if these participants were convinced that human activity has contributed to global warming. Thus, we asked, "Do you think human activity has contributed to the global warming that has occurred over the past 150 years?" The answer options were "Yes," "No," and "Don't know." (The full text of the follow-up e-mail is available in the appendix of this article.) Percentages of respondents who gave each possible response to the causation question are displayed below in Table 1 . Because of the categorical nature of these responses, they could not be used as a dependent variable for linear regression analysis. Therefore, they were transformed into a dichotomous variable for use in binary logistic regression. This variable was coded 1 for all respondents who agreed global warming is caused "mostly by human activity" and 0 for respondents who gave any other response.

LEVEL OF HARM/BENEFIT. Respondents who agreed global warming was occurring were asked the following question: "Over the next 100 years, how harmful or beneficial do you think global warming will be to people and society, if nothing is done to address it?" Response options were as follows: "very harmful," "somewhat harmful," "the harms and benefits will be more or less equal," "somewhat beneficial," "very beneficial," and "don't know." Only about $10 \%$ of respondents answered "don't know." We omitted these participants so that linear regression could be used on a continuous dependent variable ranging from "very beneficial" (coded 0) to "very harmful" (coded 4), with a midpoint of "the harms and benefits will be more or less equal" (coded 2).

ANALYSIS. Using SPSS versions 17.0 and 19.0, we examined the distributions of all variables. To compare our results to those of Doran and Zimmerman (2009), we cross tabulated the results for the initial and follow-up questions on global warming causation by area of expertise, publishing record in the last five years, and proportion of papers in the last five years that were on global warming.

To test our hypotheses, we conducted linear and logistic regressions. Global warming certainty and harm/benefit served as dependent variables in the linear regressions, and the view that global warming is/is not mostly human caused (coded 1 for all respondents who agreed global warming is mostly human caused and 0 for respondents who made any other response) served as the dependent variable in the logistic regression. In all of these analyses demographic variables, expertise, political ideology, perceived scientific consensus on global warming, and perceived conflict served as the independent variables.

It should be noted that the analyses for causation and harm/benefit only include data from the $89 \%$ of the sample who said that global warming is happening (rather than "not happening" or "don't know"). Since the other $11 \%$ did not answer the questions on global warming causation and harm/benefit, they could not be included in analyses of answers to these questions.

RESULTS. Replication of Doran and Zimmerman (2009). Table 1 shows the proportion of survey respondents-divided by their area of expertise (climate change vs meteorology and atmospheric science) and their publishing record (publishing mostly on climate change vs publishing mostly on other topics vs nonpublishing) - who report each of several different views on whether global warming is happening and what is causing it. The proportion of each group that is convinced that humans have contributed to global warming is determined by adding the proportions presented in the table's first row (respondents who indicated global warming is happening and it is mostly human caused), second row (respondents who indicated global warming is happening and it is equally human caused and natural), and the first row of the Insufficient Evidence subsection at the bottom of the table (respondents who indicated global warming is happening and although there is insufficient evidence to attribute cause with precision, human activity is implicated to some degree).

Climate science experts who publish mostly on climate change and climate scientists who publish mostly on other topics were the two groups most likely to be convinced that humans have contributed to global warming, with $93 \%$ of each group indicating their concurrence. The two groups least likely to be convinced of this were the nonpublishing climate scientists and nonpublishing meteorologists/ atmospheric scientists, at $65 \%$ and $59 \%$, respectively. In the middle were the two groups of publishing meteorologists/atmospheric scientists at $79 \%$ and $78 \%$, respectively. 


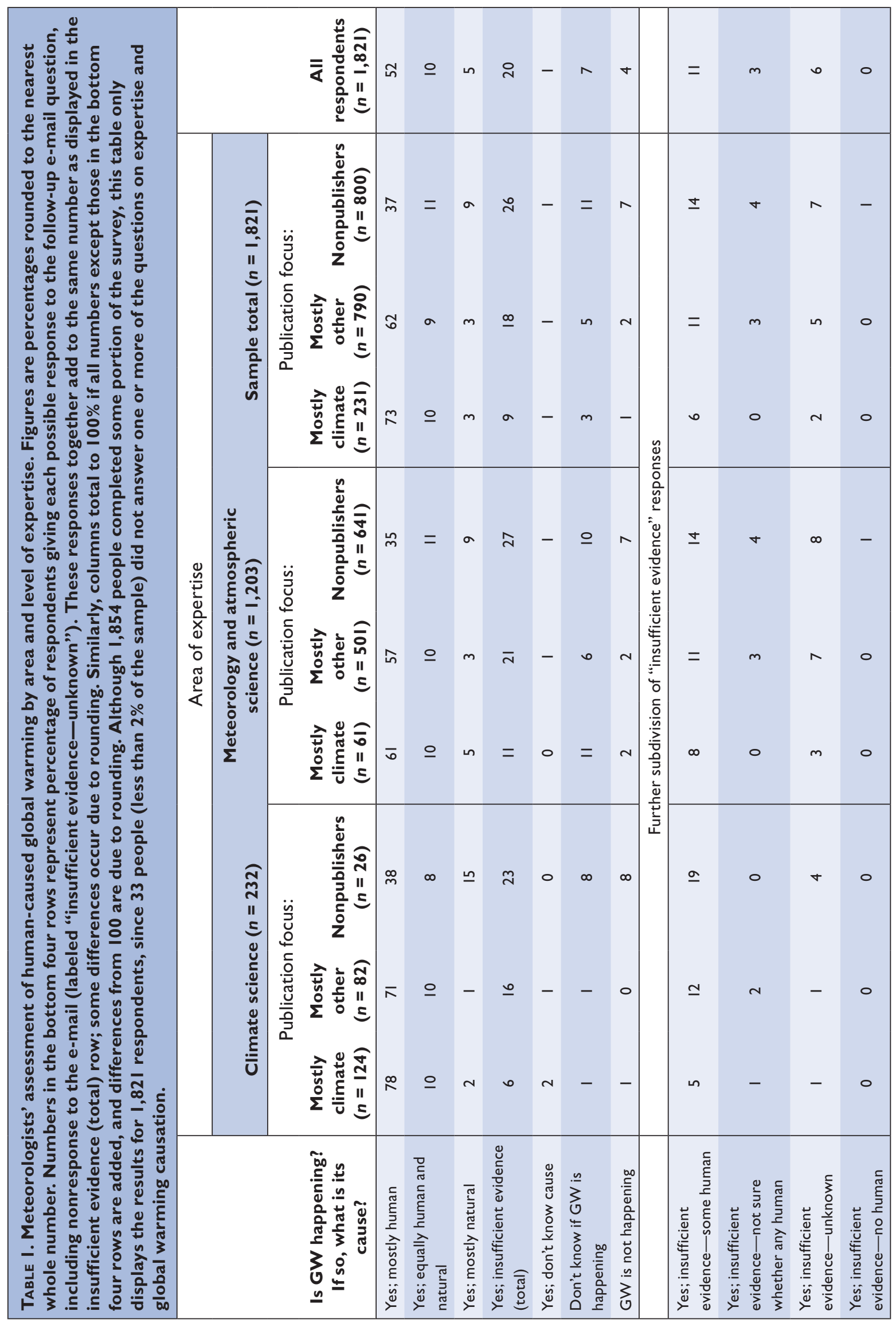


Hypothesis tests. Confirming all four hypotheses, the regression analyses showed that greater expertise, more liberal ideology, greater perceived consensus, and lower perceived conflict each predicted higher levels of certainty global warming was occurring, higher likelihood of viewing it as mostly human caused, and greater ratings of future harm. Together, the independent variables explained $37 \%$ of the variation in certainty that global warming is occurring and $29 \%$ of the variation in views on global warming harm, which is considered a moderate amount of explained variance in social science research (Cohen 1992). Because of the nature of logistic regression, an equivalent statistic is unavailable for the proportion of explained variation in views on global warming causation.

In terms of strength of the relationship between the independent and dependent variables, perceived consensus was the strongest predictor of all three types of global warming views-certainty, causation, and harm/benefit. Political ideology was the second strongest predictor of view certainty and causation, and was equivalent to perceived consensus as predictor of harm/benefit. Expertise and perceived conflict were both less strong predictors of global warming views. Expertise was the second weakest predictor of global warming certainty and the weakest predictor of causation and harm/benefit. Perceived conflict was the weakest predictor of global warming view certainty, and the second weakest predictor of causation and harm/benefit. For details of the regression analyses, see the online supplement (http://dx.doi .org/I0.II75/BAMS-D-I3-0009|.2).

DISCUSSION. Our findings regarding the degree of consensus about human-caused climate change among the most expert meteorologists are similar to those of Doran and Zimmerman (2009): 93\% of actively publishing climate scientists indicated they are convinced that humans have contributed to global warming. Our findings also revealed that majorities of experts view human activity as the primary cause of recent climate change: $78 \%$ of climate experts actively publishing on climate change, $73 \%$ of all people actively publishing on climate change, and $62 \%$ of active publishers who mostly do not publish on climate change. These results, together with those of other similar studies, suggest high levels of expert consensus about human-caused climate change (Farnsworth and Lichter 2012; Bray 2010).

Furthermore, our study was the first study of scientific professionals we know of to include expertise, political ideology, and perceived scientific consensus in a regression analysis and thus compare the potential unique effects of each in shaping global warming views. We found that perceived scientific consensus, political ideology, expertise, and perceived conflict are each, to greater or lesser degrees, associated with AMS members' views of global warming. Before considering implications of those findings, however, readers should consider two methodological issues that could have affected the accuracy of our results.

First, even though the response rate to our survey was well within the normative range, nearly threequarters of the AMS members invited to participate did not do so. This raises the possibility that our respondents may not accurately represent the views of the broader AMS membership. It is plausible, for example, that AMS members skeptical of global warming may have been less likely than the average member to respond, potentially by virtue of feeling marginalized within their professional society as a result of the views on the issue. Conversely, it is also plausible that skeptical members may have been more likely than the average member to respond, due to a desire to use the opportunity to have their views recognized by AMS leadership and other members. We have no way of directly assessing the comparability of our sample to the broader AMS population in terms of global warming views. We have, however, compared the demographics of our respondents to the demographics from an AMS membership survey conducted in 2005 (Murillo et al. 2008; $n=5,394$; survey completion rate $=48 \%$ ). Our sample had fewer students ( $1 \%$ vs $17 \%$ in 2005 , although we intentionally did not include student members in our sample), more retired members ( $11 \%$ vs $4 \%$ in 2005$)$, more older members (59\% were 50 or over vs $33 \%$ over 50 in 2005), more members with doctorates (52\% vs $38 \%)$, more members employed in research $(41 \%$ vs $31 \%$ ), and fewer female members ( $15 \%$ vs $20 \%)$. It is thus reasonable to suggest the present sample is quite similar to the overall membership of the AMS, at least demographically.

Second, our estimates of the proportion of AMS members who are convinced that global warming is occurring should be interpreted in light of an issue that arose regarding the time frame of global warming that we asked about. We asked respondents specifically about global warming that occurred over the last 150 years. However, the findings of the 2007 Intergovernmental Panel on Climate Change (IPCC) Report state that human activity has been the dominant cause of warming since the mid-twentieth century (Pachauri and Reisinger 2007, p. 39). Six respondents sent e-mails to notify us that their answers would have 
been different if we had asked about the most recent 50 -yr time frame rather than the 150-yr time frame; the time frame used in the question may have also influenced other respondents. Our results therefore may represent a more conservative estimate of the consensus on global warming than would have been obtained had we asked about a 50 -yr time frame. The relationships of the independent variables and global warming views may also have been affected by the time frame described, as we discuss further below.

Confirmation of our four hypotheses shows that meteorologists' views about global warming observed in the last 150 years are associated with, and may be causally influenced by, a range of personal and social factors. In other words, the notion that expertise is the single dominant factor shaping meteorologists' views of global warming appears to be simplistic to the point of being incorrect.

We found that perceived scientific consensus was the factor most strongly associated with AMS members' views about global warming. This suggests that scientists' thinking on scientific topics may be subject to the same kinds of social normative influences that affect the general public. Rather than rationally weighing the evidence and deciding for themselves, as would be expected under more traditional ideas of scientific judgment, scientists may also use the views of a relevant peer group as a social cue for forming their own views. Our results are consistent with those of Lewandowsky et al. (2013), who found that providing information on the scientific consensus increased the likelihood of members of the public agreeing that global warming was occurring. Our data are cross sectional, rather than experimental as in Lewandowsky et al. (2013), so we cannot be certain of the direction of the causal relationship between perceived consensus and views on global warming for AMS members. Nevertheless, the findings of Lewandowsky et al. (2013) combined with our results suggest that perceived scientific consensus may have a substantial influence on AMS members' global warming views.

Political ideology was the factor next most strongly associated with meteorologists' views about global warming. This also goes against the idea of scientists' opinions being entirely based on objective analysis of the evidence and concurs with previous studies that have shown scientists' opinions on topics to vary along with their political orientation (Nisbet 2011; Rosenberg et al. 2010). The result suggests that members of professional scientific organizations have not been immune to influence by the political polarization on climate change that has affected politicians and the general public.
We found expertise to be positively associated with meteorologists' views about global warming, concurring with previous studies on the relationship between climate science expertise and global warming views (Doran and Zimmerman 2009; Anderegg et al. 2010). This result is contrary to that found by Kahan et al. (2012b), in which members of the public with greater scientific literacy viewed climate change as a slightly less serious risk. The difference between the two studies is likely explained by the different measures of expertise. As opposed to comprehension of rudimentary scientific facts, knowledge acquired via graduate-level training and publishing in climate science does appear to increase the likelihood of viewing global warming as real, human caused, and harmful, if other factors are held constant.

While we found that higher expertise was associated with a greater likelihood of viewing global warming as real and harmful, this relationship was less strong than for political ideology and perceived consensus. At least for the measure of expertise that we used, climate science expertise may be a less important influence on global warming views than political ideology or social consensus norms. More than any other result of the study, this would be strong evidence against the idea that expert scientists' views on politically controversial topics can be completely objective.

Finally, we found that perceiving conflict at AMS was associated with lower certainty of global warming views, lower likelihood of viewing global warming as human caused, and lower ratings of predicted harm caused by global warming. This suggests that perceiving conflict within the context of their professional society may have caused AMS members to withdraw from the issue of global warming by moderating their beliefs. In addition to individual-level factors such as expertise and ideology affecting views on global warming, the polarized discursive environment in which discussion of the issue takes place may be reducing the chances of widespread engagement with it (Schweizer et al. 2011).

As our data are cross sectional, we cannot rule out an alternative possibility for the causal direction of this relationship. Rather than perceived conflict influencing views of global warming, people with skeptical views on global warming might become relatively more likely to perceive conflict at the AMS. Nevertheless, the significant relationships obtained in this study are enough to warrant further investigation of the possibility of increasing engagement through resolving conflicts at AMS.

As we mentioned above, asking about a 150 -yr time frame rather than a 50-yr time frame may also have 
changed the strength of the relationships between global warming views and other variables. For example, expertise may have been a stronger predictor of views on human causation if we had asked about a shorter time frame. Because the evidence for human causation is much stronger for the last 50 years (Pachauri and Reisinger 2007), we would expect experts, who are presumably familiar with this evidence, to be substantially more likely to view global warming in this period as human caused than nonexperts who were not familiar with the evidence. Conversely, the evidence is weaker for human causation over the past 150 years, and experts' familiarity with this weak evidence would be less likely to lead to viewing climate change as human caused. The importance of the other independent variables-perceived consensus, political ideology, and perceived conflict-we would predict to remain largely unchanged. Because these variables are not postulated to affect global warming views through direct knowledge of scientific evidence, changing a scientific detail (the 150-yr time frame) should not affect the influence these variables have on global warming views.

Although we believe our research raises more important questions than it answers, we do see some important practical implications of our findings. First, the strong relationship between perceived scientific consensus and other views on climate change suggests that communication centered on the high level of scientific consensus may be effective in encouraging engagement by scientific professionals. This exploration of views of the consensus could be accomplished via town hall-style events at professional society meetings, where participants' responses to exploratory questions are aggregated and presented back to the group for reflection, discussion, and dialogue. It could also be accomplished via "world café"-style discussion events (Brown and Isaacs 2005), such as that conducted recently by the Washington, D.C., chapter of the AMS.

Second, the relationship between political ideology and global warming views suggests that those wishing to encourage engagement should find a way to address the political differences that are likely to exist between those with different views on climate change. One way to do this could be to recognize and affirm the value of all members' political views prior to discussions of climate science. Discourse that affirms the value of diverse worldviews has shown potential to promote less polarized discussion of scientific issues where ideology has influenced differences of opinion, such as climate change (Kahan et al. 2012a).

Third, engagement efforts should include refutation of the idea that members who do not share the consensus view in climate science are lacking in expertise.
A substantial number of expert AMS members-22\% of the most expert group in our sample-do not subscribe to the position that global warming is mostly human caused. Climate experts are not completely homogenous in their views on global warming, just as climate skeptics have been shown to have a variety of nuanced opinions (Hobson and Niemeyer 2013). Any suggestion that all those with nonmajority views simply need to be "educated" is inaccurate and is likely to be insulting to a substantial number of AMS members. Discussion based on an understanding that views are more nuanced would be more productive.

Fourth, efforts to increase engagement with climate change will have minimal effects if they focus on increasing climate science knowledge alone. Although higher expertise is associated with increased tendency to view climate change as real and harmful, the increase resulting even from major gains in-such as that associated with obtaining a doctorate-seems to be quite modest. Increases in knowledge obtained through short-term campaigns are likely to be even smaller. For this reason, engagement campaigns should attempt to deal with other important factors such as consensus and political ideology as well as purely scientific information.

Finally, AMS and other organizations seeking to enhance the climate change readiness of the meteorology community should find ways to acknowledge and deal with the conflict. This may improve relations between members-a worthy goal in itself-and higher levels of willingness to engage with climate change may also result. Recently, the AMS CICCC and the other authors of this article have been involved in exploratory conflict analysis and mediation workshops with AMS members and other groups of meteorologists; the results to date of those efforts have been promising (Schweizer et al. 2011, 2014). Given the importance of the issue, continuing these efforts and/or exploring alternative conflict analysis resolution methods would appear to be a worthy priority.

In conclusion, given the potential for human society and the Earth's ecosystems to be harmed by climate change, it is imperative that members of the scientific community-and the professional societies that represent them-take all reasonable measures to ensure that what is known about the risks, and about options for managing those risks, are shared with decision makers, who should be considering that information. While the difficulties of doing this are widely acknowledged (Pidgeon and Fischhoff 2011), the problem is often attributed to the difficult dynamics associated with external communication: 
that is, sharing complex scientific information with the broader community. Our research suggests that there are also important dynamics associated with internal communication, that is, sharing information and coming to consensus within the scientific community.
ACKNOWLEDGMENTS. Ban, Bleistein, and Croft are members of the AMS's Committee to Improve Climate Change Communication. Support for this research was provided by NSF Awards DUE-1043235 and DRL-0917566. We wish to thank James Filipi and Justin Rolfe-Redding for their assistance with this research.

\section{APPENDIX: TEXT OF FOLLOW-UP E-MAIL.}

Dear fellow AMS member,

You graciously participated in a survey that I sent you in late December 2011 on behalf of the AMS Committee to Improve Climate Change Communication. Thank you.

It has become clear that one question on the survey included an answer option that is difficult to interpret without additional information.

That question—and its answer options—was:

Do you think that the global warming that has occurred over the past 150 years has been caused ...

a) Mostly by human activity

b) More-or-less equally by human activity and natural events

c) Mostly by natural events

d) I do not believe we (scientists) know enough yet to determine the degree of human or natural causation, even in the general terms stated in the categories above

e) I don’t know

You answered (d), the response option that we don't know how to interpret. We are hoping to clarify what you meant by asking you one additional question.

Do you think human activity has contributed to the global warming that has occurred over the past 150 years?

Yes

No

Don't know

Please reply to this e-mail by typing one of the following: Yes, No, or Don't Know.

If you wish to add an explanation of your answer feel free to do so, but please begin your reply with only "Yes," "No," or "Don't Know."

Thank you very much for taking the time to do this.

Best Regards,

Edward Maibach, MPH, PhD

University Professor \& Director

Center for Climate Change Communication

George Mason University, Mail Stop 6A8

Fairfax, Virginia 22030

703.993.1587

http://climatechange.gmu.edu

emaibach@gmu.edu 


\section{REFERENCES}

AMS Committee to Improve Climate Change Communication, 2011: AMS CICCC charter and terms of reference. Amer. Meteor. Soc., 4 pp. [Available online at www.ametsoc.org/boardpges/cwce/docs /BEC/CICCC/2011-02-Charter-TOR-Members.pdf.]

Anderegg, W. R. L., J. W. Prall, J. Harold, and S. H. Schneider, 2010: Expert credibility in climate change. Proc. Natl. Acad. Sci. USA, 107, 12 107-12 109, doi:10.1073/pnas.1003187107.

Bray, D., 2010: The scientific consensus of climate change revisited. Environ. Sci. Policy, 13, 340-350, doi:10.1016/j.envsci.2010.04.001.

Brown, J., and D. Isaacs, 2005: The World Cafe: Shaping Our Futures through Conversations That Matter. Berrett-Koehler Publishers, 300 pp.

Cohen, J., 1992: A power primer. Psychol. Bull., 112, 155-159, doi:10.1037/0033-2909.112.1.155.

Ding, D., E. W. Maibach, X. Zhao, C. Roser-Renouf, and A. Leiserowitz, 2011: Support for climate policy and societal action are linked to perceptions about scientific agreement. Nat. Climate Change, 1, 462-466, doi:10.1038/nclimate1295.

Doran, P. T., and M. K. Zimmerman, 2009: Examining the scientific consensus on climate change. Eos, Trans. Amer. Geophys. Union, 90, 22-23, doi:10.1029/2009EO030002.

Dunlap, R. E., and A. M. McCright, 2008: A widening gap: Republican and Democratic views on climate change. Environment, 50, 26-35.

Farnsworth, S. J., and S. R. Lichter, 2009: The structure of evolving US scientific opinion on climate change and its potential consequences. Preprints, 2009 Annual Meeting and Exhibition, Toronto, ON, Canada, SPSA, $26 \mathrm{pp}$. [Available online at http://papers.ssrn.com/sol3 /papers.cfm?abstract_id=1450804.]

- , and — 2012: The structure of scientific opinion on climate change. Int. J. Public Opin. Res., 24, 93-103, doi:10.1093/ijpor/edr033.

Fiorina, M. P., and S. J. Abrams, 2008: Political polarization in the American public. Annu. Rev. Polit. Sci., 11, 563-588, doi:10.1146/annurev .polisci.11.053106.153836.

Gorsuch, R. L., 1983: Factor Analysis. 2nd ed. Lawrence Erlbaum Associates, $425 \mathrm{pp}$.

Hobson, K., and S. Niemeyer, 2013: "What sceptics believe": The effects of information and deliberation on climate change scepticism. Public Understanding Sci., 22, 396-412, doi:10.1177/0963662511430459.

Kahan, D. M., H. C. Jenkins-Smith, and D. Braman, 2011: Cultural cognition of scientific consensus. J. Risk Res., 14, 147-174, doi:10.2139/ssrn.1549444.
-,,- T. Tarantola, C. L. Silva, and D. Braman, 2012a: Geoengineering and the science communication environment: A cross-cultural experiment. Preprints, Seventh Annual Conf. on Empirical Legal Studies, Stanford, CA, Stanford Law School, 41 pp., doi:10.2139/ssrn.1981907.

—, E. Peters, M. Wittlin, P. Slovic, L. Larrimore Ouellette, D. Braman, and G. Mandel, 2012b: The polarizing impact of science literacy and numeracy on perceived climate change risks. Nat. Climate Change, 2, 732-735, doi:10.1038/nclimate1547.

Kendall Zimmerman, M., 2008: The consensus on the consensus: An opinion survey of Earth scientists on global climate change. Ph.D. dissertation, University of Illinois at Chicago, $250 \mathrm{pp}$.

Krosnick, J. A., A. L. Holbrook, L. Lowe, and P. S. Visser, 2006: The origins and consequences of democratic citizens' policy agendas: A study of popular concern about global warming. Climatic Change, 77, 7-43, doi:10.1007/s10584-006-9068-8

Leiserowitz, A., N. Smith, and J. R. Marlon, 2010: Americans' knowledge of climate change. Yale University, $60 \mathrm{pp}$. [Available online at http://environment.yale .edu/climate/files/ClimateChangeKnowledge2010 .pdf.]

— , E. Maibach, C. Roser-Renouf, G. Feinberg, and P. Howe, 2012: Climate change in the American mind: Americans' global warming beliefs and attitudes in September, 2012. Yale University and George Mason University, 31 pp. [Available online at http:// environment.yale.edu/climate/files/Climate-Beliefs -September-2012.pdf.]

Lewandowsky, S., G. E. Gignac, and S. Vaughan, 2013: The pivotal role of perceived scientific consensus in acceptance of science. Nat. Climate Change, 3, 399-404.

Maibach, E., and Coauthors, 2012: American Meteorological Society member survey on global warming: Preliminary findings. George Mason University Center for Climate Change Communication, 19 pp. [Available online at www .climatechangecommunication.org/images/files /AMS_CICCC_Survey_Preliminary_Findings -Final.pdf.]

McCright, A. M., and R. E. Dunlap, 2011: The politicization of climate change and polarization in the American public's views of global warming, 2001-2010. Sociol. Quart., 52, 155-194.

Murillo, S. T., R. E. Pandya, R. Y. Chu, R. Czujko, J. A. Winkler, and E. M. C. Cutrim, 2008: AMS membership survey results: An overview and longitudinal analysis of the demographics of the AMS. Bull. Amer. Meteor. Soc., 89, 727-733. 
Nisbet, M. C., 2011: Climate shift: Clear vision for the next decade of public debate. American University School of Communication, 99 pp. [Available online at http:// climateshiftproject.org/wp-content/uploads/2011 /08/ClimateShift_report_June2011.pdf.]

Pachauri, R. K., and A. Reisinger, Eds., 2007: Climate Change 2007: Synthesis Report. Cambridge University Press, 104 pp. [Available online at www.ipcc.ch /publications_and_data/publications_ipcc_fourth _assessment_report_synthesis_report.htm.]

Pidgeon, N., and B. Fischhoff, 2011: The role of social and decision sciences in communicating uncertain climate risks. Nat. Climate Change, 1, 35-41.

Rosenberg, S., A. Vedlitz, D. F. Cowman, and S. Zahran, 2010: Climate change: A profile of US climate scientists' perspectives. Climatic Change, 101, 311-329, doi:10.1007/s10584-009-9709-9.
Schweizer, V., S. Cobb, W. Schroeder, G. Chau, E. Maibach, R. Henson, C. Mandryk, and J. Witte, 2011: Reframing the (discursive) environment in the climate change conflict for American weathercasters. Mediation in Environmental Conflicts Management: New Frontiers Int. Workshop, Milan, Italy, Politecnico di Milano, 9 pp.

,,,---- , and,- 2014 : TV weathercasters and climate education in the shadow of climate change conflict. Culture, Politics and Climate Change: How Information Shapes Our Common Future, D. Crow and M. T. Boykoff, Eds., Routledge, 208 pp.

Shih, T.-H., and X. Fan, 2008: Comparing response rates from web and mail surveys: A meta-analysis. Field Methods, 20, 249-271.

\section{NEW FROM AMS BOOKS!}

\section{"An engrossing account of New England's worst natural catastrophe." \\ - KeRRY EMANUEL, Professor of Atmospheric Science, MIT}

\section{Taken by Storm, 1938:}

A Social and Meteorological History of the Great New England Hurricane

\section{LOURDES B. AVILÉS}

When the Great New England Hurricane of 1938 hit the Northeast unannounced, it changed everything from the landscape, to Red Cross and Weather Bureau protocols, to the measure of Great Depression relief New Englanders would receive, and the resulting pace of regional economic recovery. The science behind this storm is presented here for the first time, with new data that sheds light on the motivations of the Weather Bureau forecasters. This compelling history successfully weaves science, historical accounts, and social analyses to create a comprehensive picture of the most powerful and devastating

hurricane to hit New England to date. 